\title{
Effects of Exogenous Indole-3-Acetic Acid on Photosynthesis of Chinese cabbage Seedlings under $\mathrm{NaCl}$ Stress
}

\author{
Yongdong $\mathrm{Xie}^{1, \mathrm{a}}$, Xuena $\mathrm{Yu}^{1, \mathrm{~b}}$, Jing $\mathrm{Yan}^{2, \mathrm{c}}$ and Yi Tang ${ }^{1, \mathrm{~d}^{*}}$ \\ ${ }^{1}$ Institute of Pomology and Olericulture, Sichuan Agricultural University, Chengdu, Sichuan, China \\ ${ }^{2}$ College of Horticulture, Sichuan Agricultural University, Chengdu, Sichuan, China \\ axydcom@sina.cn, byxn4842@sina.cn, c503619617@qq.com, dangyisunguochao@sina.com \\ *Corresponding author
}

Keywords: $\mathrm{NaCl}$ stress; Indole-3-acetic; Chinese cabbage; Photosynthesis

Abstract. A pot experiment was conducted to study the effects of exogenous indole-3-acetic acid (IAA) on photosynthesis of Chinese cabbage under $\mathrm{NaCl}$ stress. Four treatments were used in the experiment: leaves were sprayed with $50,100,150$ and $200 \mu \mathrm{mol} \cdot \mathrm{L}^{-1}$ concentrations of IAA solution, and by spraying water as control. The results showed that spraying low concentrations of IAA could improve the Pn, Tr, WUE, LUE and Gs of Chinese cabbage leaves under $\mathrm{NaCl}$ stress, and the function of high concentration of IAA was quite on the contrary. Meanwhile, the best IAA concentration of promoting photosynthesis of Chinese cabbage seedlings was $100 \mu \mathrm{mol} \cdot \mathrm{L}^{-1}$.

\section{Introduction}

Chinese cabbage (Brassica rapa ssp. pekinensis) is a cruciferous (Brassicaceae) Brassica leafy vegetables, top the list in the area of vegetable cultivation in China [1]. It is rich in nutrients, shorter growing duration, easy to cultivate, etc. [2].

Soil salinization is recognized worldwide resources and ecological problems. In China the saline land area accounted for about $1 / 3$ of Asia [3]. Soil salt ions agglomeration causes plant hydrophobia, inhibition of plant absorbing other nutrients, accumulation of reactive oxygen species in plants, damages of cell structural and obstruction plant photosynthesis $[4,5]$.

In recent years, a variety of administration of exogenous substances to improve plant resistance has become a research boom [6]. IAA also known as indole-3-acetic acid, it was the earliest plant hormone. And which plays a central role in plant adaptation to stress [7, 8]. A study had shown that spraying exogenous IAA could alleviate the damage of wheat seedling under salt stress, to some extent [9].

Currently, the research about the effect of exogenous IAA on photosynthesis of plant under $\mathrm{NaCl}$ stress was reported rarely. So this paper explored the photosynthesis change of Chinese cabbage seedlings under salt stress after spraying IAA, in the hope of providing references about Chinese cabbage cultivation in the salinized land.

\section{Materials and Methods}

Materials. The experiments were conducted at Sichuan Agricultural University $\left(30^{\circ} 42^{\prime} \mathrm{N}, 103^{\circ}\right.$ $51^{\prime}$ E), Wenjiang, China. The seeds of Chinese cabbage named quicontrol 35 were harvested in 2014 and purchased from Chengdu, China. All chemicals used in experiments were of analytical grade. Melatonin was purchased from Sigma-Aldrich (St. Louis, MO, USA).

Experimental Design. Seeds were sterilized in 10\% sodium phosphate solution for 30 minutes, flushed five times in distilled water, and then placed on 9-cm-diameter Petri dishes with three layers of filter paper moistened with distilled water and germinated at $25^{\circ} \mathrm{C}$ in darkness. Seeds were considered germinated when the seed coat was broken and a radicle was visible. After germination, seeds were planted in nutrition pot filled with vermiculite and perlite, the pot was ten centimeters in diameter and height.

Seedlings were irrigated with 20 milliliter Hoagland nutrient solution with $50 \mu \mathrm{mol} \cdot \mathrm{L}^{-1} \mathrm{NaCl}$ every other day, until the experiment finished. 
When the third leaf expanded, their leaves were sprayed with 0 (control), 50, 100, 150, 200 $\mu \mathrm{mol} \cdot \mathrm{L}^{-1}$ IAA solution until foliage and dorsal dripping. Seedlings were sprayed with IAA solution every other day, and three times in total. Each treatment consisted of 10 pots with one plant per pot. Positions of the pots were randomly changed daily to minimize positional effects. 30 days after treatment, the photosynthesis of each plant was determined by using LI-6400 portable photosynthesis meter (LI-COR Inc., USA). The photosynthetic parameters of the photosynthesis meter were manual control $\mathrm{CO}_{2}$ concentration $400 \mu \mathrm{mol} \cdot \mathrm{CO}_{2} \mathrm{~mol}^{-1}$, temperature $25^{\circ} \mathrm{C}$, light intensity $1000 \mu \mathrm{mol} \mathrm{m} \mathrm{m}^{-2} \cdot \mathrm{s}^{-1}$. The determination of photosynthetic parameters were net photosynthetic rate $(\mathrm{Pn})$, transpiration rate $(\mathrm{Tr})$, stomatal conductance $(\mathrm{Gs})$ and $\mathrm{CO}_{2}$ concentration of intercellular $(\mathrm{Ci})$, and each treatment was repeated three times. Water use efficiency $(\mathrm{WUE})=$ net photosynthetic rate $(\mathrm{Pn}) /$ transpiration rate $(\mathrm{Tr})$, Light use efficiency $(\mathrm{LUE})=$ net photosynthetic rate $(\mathrm{Pn}) /$ light intensity[10].

Statistic analyses. Statistical analyses were performed using SPSS 13.0 statistical software (IBM, Chicago, IL, USA). Data were analyzed by one-way ANOVA with least significant difference (LSD) at a 5\% confidence level.

\section{Results and Discussion}

Net Photosynthetic Rate (Pn). Compared with control, the sprayed concentration of 50, 100, and $150 \mu \mathrm{mol} \cdot \mathrm{L}^{-1}$ could improve the net photosynthetic rate of Chinese cabbage under $\mathrm{NaCl}$ stress, which were higher $13.11 \%(P>0.05), 40.83 \%(P<0.05), 16.08 \%(P>0.05)$ than control separately (Fig. 1). When spraying concentration of IAA was $200 \mu \mathrm{mol} \cdot \mathrm{L}^{-1}$, the $\mathrm{Pn}$ was lowest, which was reduced by $6.7 \%(\mathrm{P}>0.05)$ compared with control.

Transpiration Rate (Tr). After spraying IAA, the Tr of Chinese cabbage seedlings was increased compared with control (Fig. 2). When the concentration of IAA was $100 \mu \mathrm{mol} \cdot \mathrm{L}^{-1}$, the $\operatorname{Tr}$ was maximum, which was $131.33 \%(P<0.05)$ of control. Thereafter, with the increase of the concentration of IAA, $\operatorname{Tr}$ of Chinese cabbage decreased slightly, but there was no significant difference with the treatment that sprayed $100 \mu \mathrm{mol} \cdot \mathrm{L}^{-1}$ IAA.

Water Use Efficiency (WUE). It was clearly observed that spraying 50 and $100 \mu \mathrm{mol} \cdot \mathrm{L}^{-1} \mathrm{IAA}$ had little effect on WUE of Chinese cabbage seedlings, which increased only $3.65 \%$ and $7.32 \%$, than control ( Fig.3). When the IAA concentration exceeded $100 \mu \mathrm{mol} \cdot \mathrm{L}^{-1}$, the WUE of Chinese cabbage seedlings suppressed.

Light Use Efficiency (LUE). With the increasing of IAA concentration, the LUE of Chinese cabbage rose at beginning then declined, and got to the highest at the concentration of IAA was $100 \mu \mathrm{mol} \cdot \mathrm{L}^{-1}$, which enhanced $40.83 \% \quad(P<0.05)$ than control( Fig.4). But when the $\mathrm{sg}$ concentration was $200 \mu \mathrm{mol} \cdot \mathrm{L}^{-1}$, the LUE was lower than control, but no significant difference with control. 


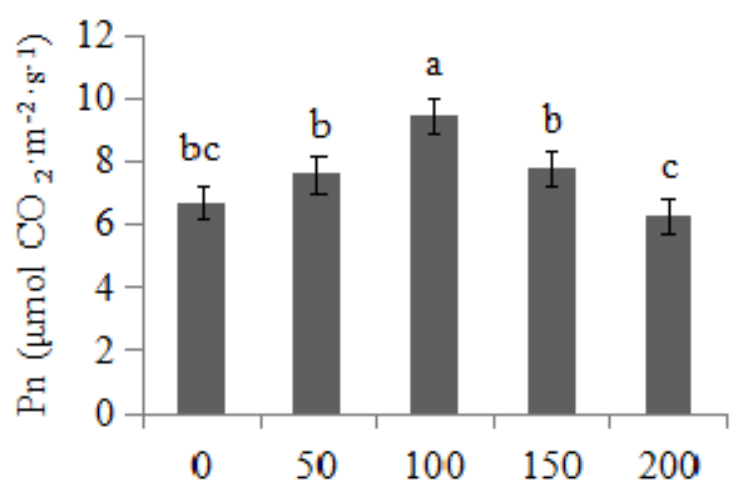

IAA concentration $\left(\mu \mathrm{mol} \cdot \mathrm{L}^{-1}\right)$

Fig. 1 Pn of IAA sprayed Chinese cabbage

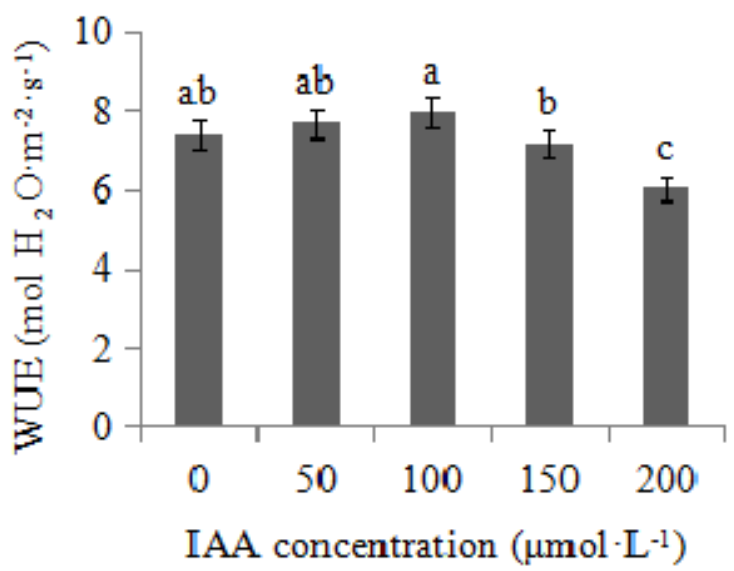

Fig. 3 WUE of IAA sprayed Chinese cabbage

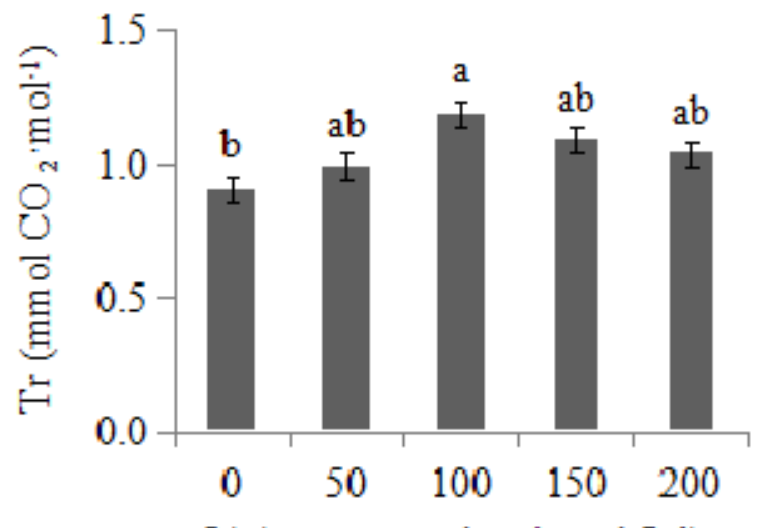

IAA concentration $\left(\mu \mathrm{mol} \cdot \mathrm{L}^{-1}\right)$

Fig. 2 Tr of IAA sprayed Chinese cabbage

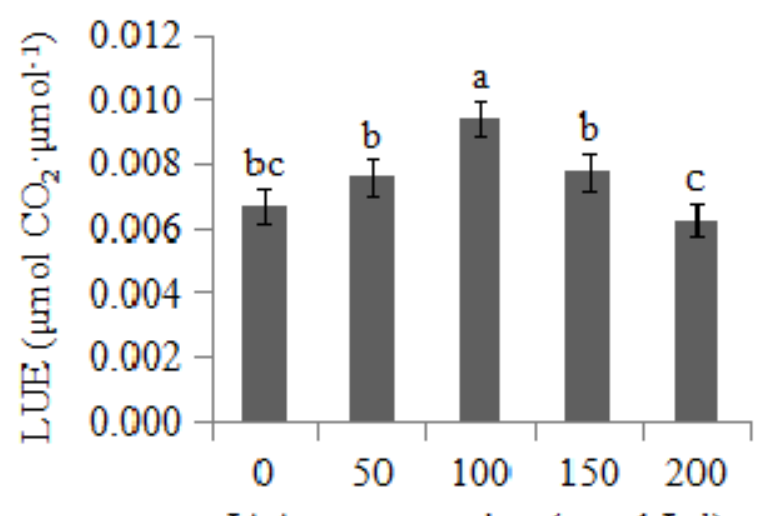

IAA concentration $\left(\mu \mathrm{mol} \cdot \mathrm{L}^{-1}\right)$

Fig. 4 LUE of IAA sprayed Chinese cabbage

Stomatal Conductance (Gs). The same as

the trend of $\mathrm{Tr}$, compared with control, spraying $100 \mu \mathrm{mol} \cdot \mathrm{L}^{-1} \mathrm{IAA}$ significantly increased stomatal conductance of Chinese cabbage seedlings under $\mathrm{NaCl}$ stress, Gs was enhanced by $38.46 \%$ $(P<0.05)$. These treatments of other concentrations were no significant difference with control.

$\mathbf{C O}_{2}$ Concentration of Intercellular (Ci). As shown in Fig. 6, there was almost no difference between the $\mathrm{Ci}$ in Chinese cabbage after spraying IAA, though the $\mathrm{Ci}$ was the highest when the concentration of IAA was $100 \mu \mathrm{mol} \cdot \mathrm{L}^{-1}$.

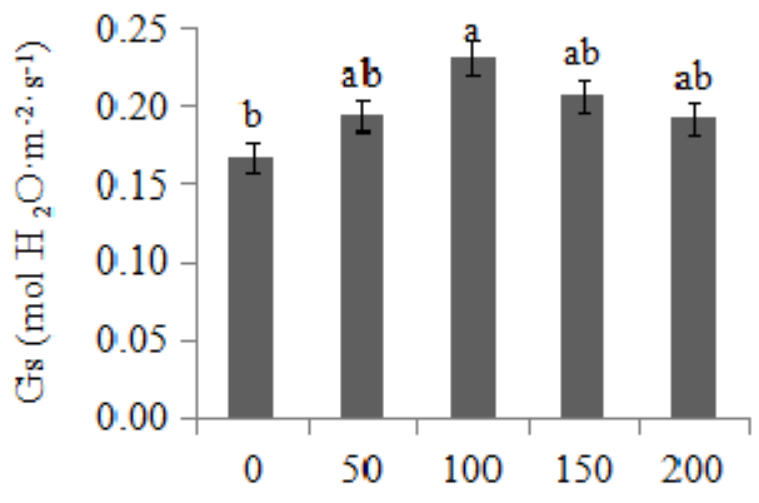

IAA concentration $\left(\mu \mathrm{mol} \cdot \mathrm{L}^{-1}\right)$

Fig. 5 Gs of IAA sprayed Chinese cabbage

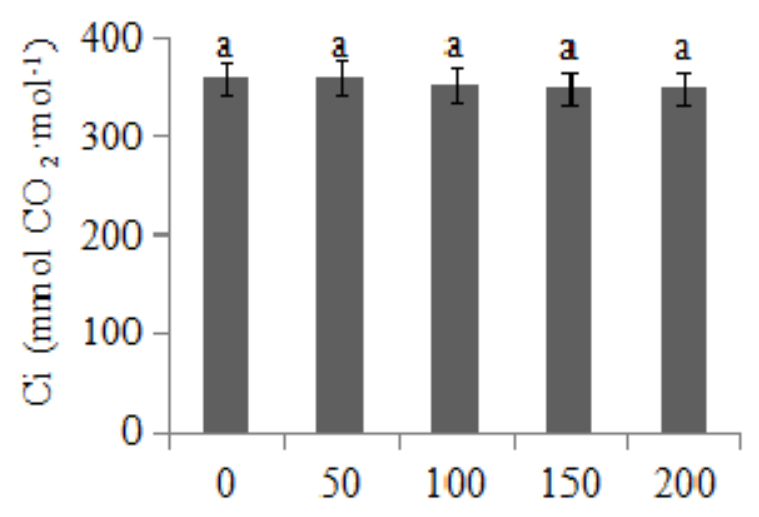

IAA concentration $\left(\mu \mathrm{mol}-\mathrm{L}^{-1}\right)$

Fig. 6 Ci of IAA sprayed Chinese cabbage

When the plant was under stress, photosynthesis can react quickly. Wei et al stated that exogenous IAA can promote the leaf area of soybean seedlings under $\mathrm{NaCl}$ stress, and improve the 
leaf photosynthetic capacity[11]. The results of this experiment showed that spraying low concentrations of IAA could improve Pn, Tr, WUE, LUE and Gs of Chinese cabbage seedlings under $\mathrm{NaCl}$ stress, but high concentrations of IAA could inhibit photosynthesis. To sum up, spraying appropriate concentration of IAA can improve photosynthetic efficiency of Chinese cabbage leaves, and the best sprayed concentration of IAA is $100 \mu \mathrm{mol} \cdot \mathrm{L}^{-1}$.

\section{Acknowledgements}

This work was financially supported by the Sichuan Agricultural University "Shuang-Zhi Plan" Foundation, Sichuan Provincial Department of Education Foundation (15ZA0011).

\section{References}

[1] W. Zhang, J. Z. Cui and S. C. Yu: Molecular Plant Breeding Vol.11 (2013), p.843-857 (In Chinese).

[2] L. Lin, J. Zhou and Q. X. An: Ecological Science Vol.32 (2011), p. 2430-2435 (In Chinese).

[3] F. F. Xu, L. M. Ye and X. Xu: Subtropical Plant Science Vol.39 (2010), p. 18-20 (In Chinese).

[4] S. H. Yang, J. Ji and G. Wang: World Sci-tech R \& D Vol.28 (2006), p. 70-76 (In Chinese).

[5] R.Guo, F. Li and J. Zhou: Chinese Journal of Plant Ecology Vol.40 (2016), p. 69-79 (In Chinese).

[6] D. Y. Gu, X. F. Wang and F. J. Yang: Northern Horticulture Vol.03 (2016), p. 195-198 (In Chinese).

[7] X. X. Li, J. Zhao and H. Liao: Plant Physiology Journal Vol.49 (2013), p. 573-578 (In Chinese).

[8] J. E. Park, J. Y. Park and Y. S. Kim: Journal of Biological Chemistry Vol.282 (2007), p. 10036-10046.

[9] J. Liu, X. L. Ma and X. W. Shang: Journal of Gansu Agricultural University Vol.44 (2009), p. 47-51(In Chinese).

[10]X.J. Jiang, H. Wang and W. Peng: Shanxi Journal of Agricultural Sciences Vol. 54 (2008), p.56-58 (In Chinese).

[11]A. L. Wei, Y. Z. Chen: Acta Botanica Boreali-Occidentalia Sinica Vol. 20 (2000), p.410-58 (In Chinese). 